\title{
Schedule-induced attack on a pictorial target in feral pigeons (Columba livia)
}

\author{
BYRON C. YOBURN and PERRIN S. COHEN \\ Northeastern University, Boston, Massachusetts 02115
}

\begin{abstract}
Two of three feral pigeons exhibited schedule-induced attack on a colored photograph of a conspecific during exposure to a fixed-time food schedule. The rate and pattern of attack were comparable to that observed with domesticated pigeons. Schedule-induced attack against a conspecific target image is not confined to domesticated birds.
\end{abstract}

Domesticated pigeons have been used exclusively in studies of schedule-induced attack with restrained live (Azrin, Hutchinson, \& Hake, 1966; Gentry, 1968), taxidermically stuffed (Flory, 1969), mirror (Cohen \& Looney, 1973), and pictorial (Looney \& Cohen, 1974; Looney, Cohen, \& Yoburn, 1976) targets. This experiment evaluates the generality of these results with respect to domestication. Specifically, this experiment determines if schedule-induced attack against a pictorial, conspecific target also occurs in feral pigeons that lived in a "natural" environment up to the time of experimentation.

\section{METHOD}

\section{Subjects}

Three feral pigeons (F4, F5, F6) of unknown age and sex were trapped in the Fenway area of Boston, Massachusetts. Following arrival in the laboratory, the animals were quarantined with free access to food, water, and grit for 6 weeks. Animals were then moved to the main colony room and reduced to $75 \%$ of their ad-lib weights with water and grit continuously available. Supplementary feedings were given following test sessions as required to maintain stable deprived body weights.

\begin{abstract}
Apparatus
Two $33.0 \times 35.9 \times 34.9 \mathrm{~cm}$ black test chambers were located in a dark sound-attenuated room equipped with a video monitoring camera. Chamber illumination was provided by six 1.6-W houselights located behind a ground glass shield on the roof of each chamber. Exhaust fans and white noise partially masked extraneous sounds. In each chamber, food was delivered by a hopper located behind a $5.1 \times 5.8 \mathrm{~cm}$ opening centered on one $33.0 \times 34.9 \mathrm{~cm}$ wall. A photocell and a light were mounted inside each hopper enclosure. Centered on the wall opposite the hopper was a $15.3 \times 12.1 \mathrm{~cm}$ photograph of an unfamiliar gray feral pigeon in a posture similar to that used in our studies of schedule-induced attack with domesticated pigeons (Looney et al., 1976). The photograph was covered with a protective layer of Scotch Brand Magic Mending tape and mounted on a piece of Plexiglas that was suspended from two frame-mounted microswitches. A force of approximately
\end{abstract}

This research was supported in part by U.S. Public Health Service Grants RR 07143 and R01 MH25514-01 to Northeastern University. We thank Mary-Thomas Turnock for her comments. Reprints may be obtained from Byron C. Yoburn, Department of Psychology, Northeastern University, 360 Huntington Ave., Boston, Massachusetts 02115.
$.1 \mathrm{~N}$ or greater applied to any point on the target closed one of the switches and was defined as one target response.

\section{Procedure}

Birds were exposed to the late target introduction procedure described by Looney et al. (1976). Birds were given seven 20 -min sessions in the chamber without the target or the food schedule. In the absence of the target, birds were magazine trained in one session and then exposed to a series of fixed-time (FT) food schedules in which food was delivered independently of the bird's behavior. Each of the $107-\mathrm{sec}$ food deliveries was timed from the interruption of the photocell inside the hopper. Animals were exposed to five sessions of FT 5, 10, 15,30 , and $60 \mathrm{sec}$ and then 40 sessions of FT $90 \mathrm{sec}$. On the 26 th session of the FT 90-sec schedule, the colored photograph of the conspecific was introduced into the chamber for the remainder of the experiment, and a protective contingency was programmed to delay a scheduled food delivery until responding on the target had not occurred for $10 \mathrm{sec}$. Birds that had median target response rates of less than 1.0 responses/min during the first 15 sessions of exposure to the target were discarded from the experiment. Subject F4 was transferred to a new test chamber after the 40th session on the FT 90-sec schedule. This animal was given 10 sessions in the new chamber with the same target and schedule conditions. Following 15-25 sessions on the FT 90-sec schedule with the target available, pigeons were exposed to $1515-\mathrm{min}$ sessions with no food, followed by reinstatement of the FT 90 -sec schedule for 10-15 sessions.

\section{RESULTS AND DISCUSSION}

The results of this experiment with feral pigeons are similar to those obtained with domesticated White King pigeons in our previous work (e.g., Looney et al., 1976). Figure 1 plots rate of target contact (total target responses/total session time) as a function of successive sessions for the two of three feral birds (upper two panels) that exhibited sustained levels of attack (median response rate greater than 1.0 responses/min) and for a representative domesticated White King pigeon (lower panel) from Looney et al. (1976). The horizontal lines correspond to the median attack rate during the last five sessions of each condition. The domesticated bird was exposed to the same late target procedure used in this experiment except that the no-food condition continued for 20 sessions. The finding that two of three feral pigeons showed sustained rates of attack 


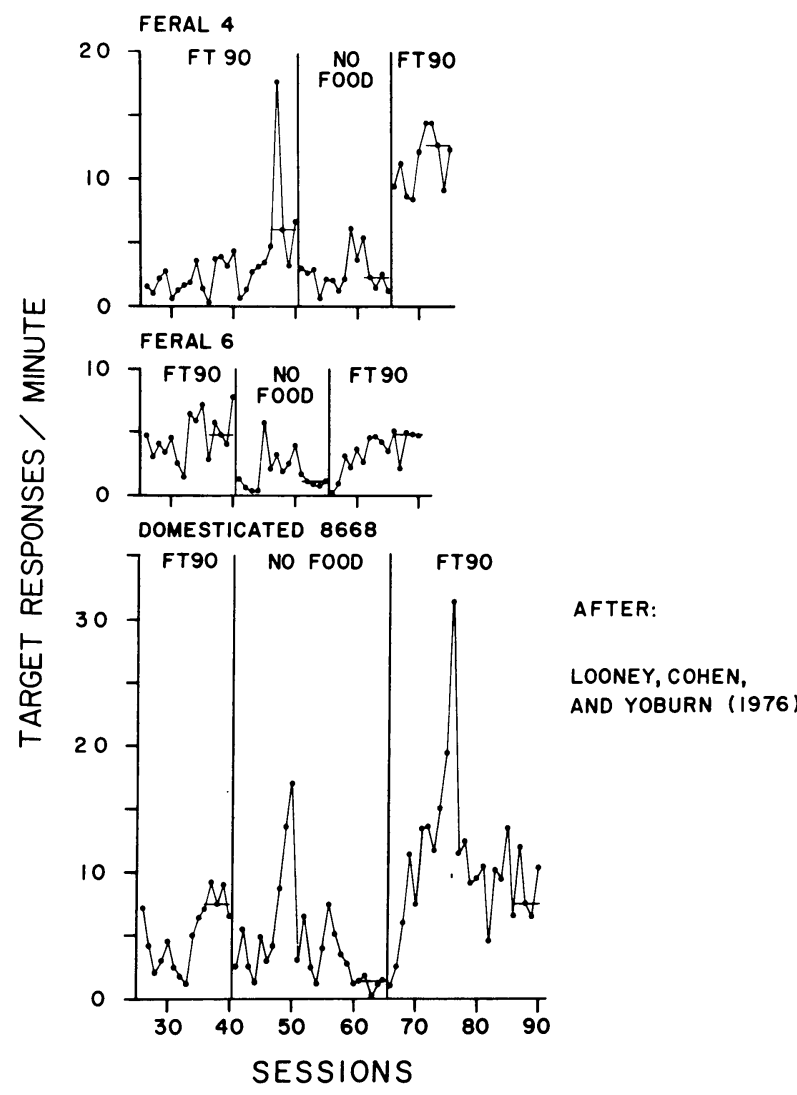

Figure 1. Rate of target contact on a colored photograph of a conspecific as a function of successive sessions for two of three feral pigeons and one domesticated pigeon (after Looney, Cohen, \& Yoburn, 1976). The target was introduced on the 26th session on the FT 90-sec schedule for all birds. Median attack rate over the last five sessions of each condition is indicated by the horizontal lines.

against the pictorial target is consistent with previous results (Looney et al., 1976) with domesticated pigeons.

As shown in Figure 1, overall rate of attack, as well as between-sessions variability of rate, for the feral birds was similar to that of the domesticated pigeon. For both feral and the domesticated pigeons, removal and subsequent reinstatement of the food schedule resulted in a corresponding decrease and then increase in median attack rate over the last five sessions of each condition. In spite of the decrease, both the feral and domesticated birds continued to attack the pictorial target with median rates during the last five sessions of 1.0 responses/min or greater.

Both feral pigeons exhibited the typical postreinforcement pattern of attack that was reported for domesticated pigeons exposed to the same schedule condition (e.g., Yoburn \& Cohen, in press). Videotaped recordings indicated that the feral birds, like domesticated ones (Looney \& Cohen, 1974; Looney et al., 1976) charged and pecked at the head and eye of the conspecific target. In addition, attacks were frequently accompanied by guttural vocalizations similar to those observed with domesticated birds (Rashotte, Katz, Griffin, \& Wright, 1975).

In summary, the present data add generality to previous experiments by showing that schedule-induced attack against a conspecific target image is not confined to domesticated birds. Whether this generalization extends to more subtle properties of schedule-induced attack such as control by specific target features (Cohen, Yoburn, Pennington, \& Ball, in press) remains to be determined.

\section{REFERENCES}

Azrin, N. H., Hutchinson, R. R., \& HaKe, D. F. Extinctioninduced aggression. Journal of the Experimental Analysis of Behavior, 1966, 9, 191-204.

Cohen, P. S., \& Looney, T. A. Schedule-induced mirror responding in the pigeon. Journal of the Experimental A nalysis of Behavior, 1973, 19, 395-408.

Cohen, P. S., Yoburn, B. C., Pennington, R. V., \& Ball, R. Visual target control of schedule-induced aggression in White King pigeons (Columba livia). Aggressive Behavior, in press.

Flory, R. K. Attack behavior as a function of minimum interfood interval. Journal of the Experimental Analysis of Behavior, $1969,12,825-828$.

GentRY, W. D. Fixed-ratio schedule-induced aggression. Journal of the Experimental Analysis of Behavior, 1968, 11, 813-817.

Looney, T. A., \& Cohen, P. S. Pictorial target control of schedule-induced attack in White Carneaux pigeons. Journal of the Experimental Analvsis of Behavior, 1974, 21, 571-584.

Looney, T. A., Cohen, P. S., \& Yoburn, B. C. Variables affecting establishment of schedule-induced attack in White King pigeons. Journal of the Experimental Analysis of Behavior, 1976, 26. $346-360$.

Rashotte. M. E., Katz, H. N., Griffin, R. W., \& Wright, A. C. Vocalizations of White Carneaux pigeons during experiments on schedule-induced aggression. Journal of the Experimental Analysis of Behavior, 1975, 23, 285-292.

Yoburn, B. C., \& Cohen, P. S. Assessment of attack and drinking in White King pigeons on response-independent food schedules. Journal of the Experimental Analysis of Behavior, in press.

(Received for publication October 26, 1978.) 